\title{
OTROS DATOS SOBRE LA TRAYECTORIA DE LA PALABRA «LITERATURA» EN CASTELLANO
}

\author{
Francisco Abad
}

\author{
Universidad Nacional de Educación a Distancia
}

La filología moderna tiene muy descuidada la historia literaria de las palabras, sin haber hecho en ella [...] adelantos.

Ramón Menéndez Pidal ${ }^{1}$

\section{SOBRE «LITERATURA»: DATOS PRELIMINARES}

Vamos a llevar a cabo algunas anotaciones acerca de la marcha de la palabra literatura en nuestra lengua: estamos ante una de las palabras fundamentales del ámbito de la filología que aún espera la reconstrucción en detalle de su historia, historia que por supuesto no hemos trazado tampoco nosotros por completo todavía ${ }^{2}$.

\footnotetext{
1 Partimos una vez más de una sugerencia pidalina, por tener a don Ramón como una fuente de magisterio y estímulo inagotada, se coincida o no con él en todo.

2 Nos hemos referido a «La trayectoria de "literatura" y de "novela" en castellano" en el cap. XXIII de Abad (2000). Llevamos ahora más allá la investigación, y no repetimos
} 
García de Diego no consignó la voz en su Diccionario Etimológico (i!), mientras el Diccionario Crítico Etimológico de J. Corominas trae la palabra como cultismo, e indica que «antes se dijo letradura», cosa que en efecto ocurre por ejemplo en don Juan Manuel, quien en el Libro enfenido escribe así: «Et despues que fueren entendiendo, yr les mostrando poco a-poco todas las cosas por que pueden ser muy sabidores; tan bien en la letradura quanto les cunple de saber, commo en saber todo lo que cunple de caualleria, et de commo [...]».

Corominas no advierte sin embargo que en los textos juanmanuelinos el vocablo significa «conocimientos»; por su lado Robert Escarpit ha sintetizado en su conocido análisis sobre «La definición del término "literatura"», cómo esta voz, «copia del latín litteratura, [...] no parece haber sido empleada habitualmente en inglés, castellano, francés e italiano antes de los últimos años del siglo $X V »$ ». Desde luego Escarpit subraya en un momento que el vocablo poseerá las dos nociones de «literatura como fenomenología intelectual» y «literatura como creación estética».

\title{
EL PRIMER SETECIENTOS
}

Un párrafo de Menéndez Pelayo resultó clarificador hace muchos años, y por esa clarificación que introduce debe repetirse otra vez:

\begin{abstract}
Pero es forzoso recordar — decía don Marcelino en la Historia de las ideas estéticas en España- el sentido que a la palabra literatura daban el abate Andrés y sus contemporáneos. Descaminados por el valor etimológico, y pagando tributo al espíritu enciclopédico de la época, no acertaban a determinar la profunda diferencia que media entre las obras científicas y las puramente literarias. Estando en mantillas la ciencia estética, no concebían clara y distintamente la idea del arte como expresión de la belleza, y la confundían con la idea de la ciencia, cuyo objeto es la investigación de la verdad. Por tal manera ensanchaban considerablemente los límites de la literatura, que abarcaba no ya sólo las bellas letras, sino las ciencias filosóficas, las exactas, las naturales, con todos sus ramos y aplicaciones.
\end{abstract}

los datos que tenemos dados ya, salvo que resulte necesario tenerlos presentes en la coherencia de lo que decimos; por lo demás pensamos que una referencia a la voz literatura en castellano no debiera encontrarse ausente - como de hecho se halla - de las diferentes Historias de la lengua que vienen publicándose en estos lustros últimos. 
Ciertamente la voz literatura en el sentido de «arte que tiene por instrumento la palabra» no lo tenía quizá la mayor parte de las veces en nuestro Setecientos, pues solía referirse a la totalidad de los conocimientos en letras y en ciencias, a la sabiduría en general; por ejemplo al inicio del Diario de los literatos de España se alude a don Juan Martínez Salafranca, y se dice que «con el titulo de Memorias Eruditas para la Critica de Artes, y Ciencias» tuvo intención de «mostrar à nuestros Patricios los progressos de la Literatura Estrangera».

Hacia 1741/1745 redactó Fray Martín Sarmiento las Memorias para la historia de la poesia, y poetas españoles; las hemos leído al completo, y en ellas comprobamos más de una vez este sentido de «erudición, sabiduría» que tiene la palabra; no obstante habla en un momento de «la Poesía» y manifiesta entonces:

\begin{abstract}
Consiguiente á esto ha sido el que nada inclinado, ó acaso averso á aquel dulce género de literatura, mirase con la misma indiferencia todo lo que pertenece á la Historia literaria de los Poetas, y sus Poesías. Verdad es que, por no ser totalmente averso á la Historia literaria en general, tal vez he tropezado con esta, ó la otra noticia de la edad, vida, y circunstancias de Poetas Griegos, y Latinos; pero rarísima vez con exâctas noticias de la Poesía, y Poetas Españoles.
\end{abstract}

Ahora Fray Martín se refiere al «dulce género» literario de la poesía, y emplea la expresión Historia literaria en el sentido artístico-verbal: se trata de la que se ocupa de la historia de la poesía, no ya de la historia enciclopédica de cualesquiera letras - aunque también alude a la «Historia literaria en general»-, y en la misma acepción moderna aparece la propia voz literatura cuando por ejemplo alude a la «Literatura Oriental» a la que se habían aficionado los mozárabes de Córdoba.

Literatura es también ahora «poesía», y se comprueba cómo Sarmiento resulta un autor de relieve para nuestro objeto - lo es, desde luego, para la historia de las ideas lingüísticas en España, y para la historia de la historiografía literaria-: en él coexisten ejemplos del sentido dieciochesco y enciclopédico de la palabra literatura y el sentido actual de la misma, y además en él aparece (asimismo con el valor actual) la expresión «Historia literaria»; estamos desde luego en una cronología temprana, en los años cuarenta del Setecientos. 


\section{IGNACIO DE LUZÁN}

Lógicamente el vocablo literatura ha de hallarse presente en las Memorias literarias de Paris de Luzán (1751). Ya en el «Dictamen» preliminar acerca de la obra por el Padre Aravaca, aparece la voz varias veces y todas en el sentido de «saber», por ej.: «Assi enseñaban en nuestras Universidades, en donde se dictaba sobre las Artes, las Ciencias, las Lenguas Orientales, y todo genero de Literatura»; «Pero se aumenta, y perfecciona el gusto en materias de Literatura con la continua leccion de buenos Libros, la atenta meditacion sobre lo que contienen, la conversacion con hombres sabios, y experimentados, y el cotejo, que se hace de unas mismas cosas entre varios Autores que las tratan»; etc. Asimismo se alude al «actual estado de nuestra Literatura» en referencia a la situación de la cultura española a mitad de la centuria.

Luego en las páginas del texto propiamente dicho Luzán anuncia que su exposición tratará «de la Literatura francesa», es decir, del estado del saber y de los conocimientos en Francia, de la situación de su cultura, y lo mismo repite poco más adelante (cuando alude al intento de «hablar de su literatura»). De hecho al abate Nollet, que era un «ilustre Sábio de la Academia de las Ciencias», lo denomina también «literato», y en definitiva estas Memorias literarias no tratan sólo de la poesía, las tragedias o las comedias francesas y los teatros de París, sino por igual de la Filosofía, las Matemáticas, la Medicina, etc.: constituyen unas Memorias acerca de la situación del saber y de la cultura en París.

\section{FORNER Y SEMPERE}

Hay un texto de importancia en nuestro Setecientos - no hace falta decirlo- que es el de las Exequias de la lengua castellana de Juan Pablo Forner; en el mismo nos parece advertir la significación de «saber» del vocablo y también la acepción moderna de la palabra: ambas acepciones - según nuestro sentimiento lingüístico- aparecen una u otra vez vinculadas al significante literatura.

El pasaje «en ella investiga las causas y orígenes del que él llama mal gusto en la literatura española» creemos que ilustra la significa- 
ción «arte verbal» de la palabra, al igual que la ilustran los empleos que hace el autor al escribir «nuestra literatura», «qué el escritor de coplas y el escritor de sátiras, y el escritor de cuentos de literatura?», o «no puede expiarse con menos desagravio el desacato horrible con que los ganapanes de la literatura han violado la castidad hermosa de nuestra lengua».

Creemos que sin embargo el vocablo acentúa su referencia al saber en general cuando nuestro autor escribe «murió para la literatura», o cuando escribe asimismo: «filósofo infernal, nacido, como otros menguados de tu infeliz patria, para convertir su literatura en monstruo horrible $[, \ldots] »$.

Asimismo aparece nuestra voz en las Reflexiones sobre el buen gusto en las ciencias, y en las artes. Traduccion libre de las que escribio en italiano Luis Antonio Muratori, [...] por Don Juan Sempere y Guarinos, y en particular en el «Discurso sobre el Gusto actual de los Españoles en la Literatura» que puso Sempere al final de esta obra de 1782. En el presente «Discurso» literatura creemos que significa siempre «saber, erudición», y la fórmula «Historia Literaria» es Historia de cualesquiera conocimientos: «Historia Literaria» es para el autor la España Sagrada del Padre Flórez, etc.; de tal manera ocurre así que la expedición que hizo Jorge Juan al Perú acompañando a los Académicos de Ciencias de París es llamada por Sempere «expedicion literaria».

\section{LOS JESUITAS EXPULSOS}

Terreros define literatura según el significado más propio entonces, a saber, «doctrina y conocimiento profundo de las letras ó ciencias»; de esta manera un literato es un «hombre sabio, erudito, crítico, que sabe las buenas letras, que explica y comenta los Autores».

Del abate Lampillas vamos a atender a un volumen: el Ensayo historico-apologetico de la literatura Española [...]. Parte Segunda de la literatura moderna. Tomo Primero (1783). Don Xavier Lampillas manifiesta casi al inicio de su texto que

si bien es cierto que España ha sido siempre fecunda de ingenios muy amenos que han dado infinito honor à las bellas letras; con todo no puede negarse que los estudios sagrados y sòlidos son los que forman peculiarmente la literatura Española. 
«Literatura» es aquí el conjunto de los saberes escritos, y por eso puede decir el autor también cómo «en vano pretenderà este nombre en algunos paìses el que no tuviere un baño de todas las partes de la literatura».

Las ciencias matemáticas y filosóficas que propagaron «los Arabes» en la Península constituyen — según escribe Lampillas - una «literatura apreciada», quien por otra parte habla de la fama «en toda especie de literatura» que adquirió Andrés Laguna.

El abate Xavier Lampillas entiende pues por literatura en las páginas presentes que hemos examinado, el conjunto de escritos acerca de cualquier saber, o también esos mismos saberes y conocimientos.

Texto obligado que debemos atender asimismo es el de Juan Andrés Origen, progresos y estado actual de toda la literatura. El «Prefacion del autor» al Tomo I (1784) estampa el propósito del autor, que no es sino el de dar cuenta del estado de la sabiduría o literatura:

Mi intento - escribe- $-[. .$.$] es dar una perfecta y cabal idéa del estado de$ toda la literatura, qual no creo se encuentre en autor alguno. [...] Deberémos, pues, dar en esta obra una exacta noticia de los progresos de todas y de cada una de las partes de la literatura. [...] Es preciso dividir en varias clases las ciencias para evitar confusion, y seguir algun orden y distincion en la inmensa multitud de tantas materias.

La literatura es por tanto un conjunto numeroso de materias, un saber del que cabe dar cuenta en sus progresos y su estado: decir literatura equivale en realidad a decir «cultura»: "¿qué vasto y delicioso campo no nos presenta la literatura griega [...]», escribe por ejemplo Andrés.

La literatura es el saber en su conjunto, y así nuestro autor puede escribir también:

La literatura moderna reconoce por su madre á la arábiga, no solo en las ciencias, sino tambien en las buenas letras.

La cultura o saber modernos (a ellos alude) poseen un origen arábigo, establece el abate Andrés. 


\section{IRIARTE}

En 1787 aparece la Coleccion de obras en verso y prosa de D. Tomas de Yriarte en sus tomos IV y VI, el primero de ellos «que comprehende la Traduccion en verso de la Epístola de Horacio á los Pisones, y $[\ldots]$ », y el segundo «que comprehende varias obras críticas»; hemos analizado una de las obras del segundo de tales volúmenes, y en ella encontramos pasajes que nos importan. En las palabras iniciales de ese Tomo VI «Al Lector», manifiesta ya Iriarte:

En el Diálogo joco-serio intitulado Donde las dan las toman se explica el sentido de varios lugares difíciles de la Epístola de Horacio á los Pisones, se exâmina el mérito de algunas Poesías Castellanas insertas en la Coleccion del Parnaso Español, y se notan muchas equivocaciones sobre las vidas de diferentes Poetas nuestros. Esto puede conducir al bien de la Literatura, y por sola esta razon se publica.

El vocablo literatura lo emplea nuestro autor en el sentido semánticamente restringido que hace referencia a las obras de arte verbal; en otro momento, sin excluir este mismo sentido, podría entenderse también el de «situación cultural de la nación»:

El que pueda adelantar mas en la materia - exclama Iriarte-, haga una traduccion y publíquela; que si fuere mejor que la mia, me alegraré de todo corazon por el bien de la Literatura Española, que importa mas que mi crédito y que mi amor propio. Así pienso y debo pensar.

Sin embargo en otros momentos reaparece la significación actual y usual de literatura, como cuando Iriarte habla del estado de la nación en materia de «literatura» o conocimiento de las bellas letras, cuando habla de «nuestra literatura» o serie literaria, o cuando cita a Sedano, quien en referencia a su Parnaso Español había manifestado: «Puedo lisonjearme de que hasta ahora no ha habido pensamiento más feliz en la Nacion en materia de Literatura».

En fin en Moratín se documenta por lo menos el sentido de «conjunto de las producciones artístico-verbales de una nación», pues en efecto don Leandro se refirió por ejemplo a «los no vulgares conocimientos $[\ldots]$ de nuestra lengua, de nuestra literatura, historia y costumbres» que anunciaban las obras de un escritor francés a quien menciona. 
El Padre Sarmiento, o Sedano e Iriarte, etc., emplean en el Setecientos la palabra literatura en el sentido luego más general de «arte que tiene por instrumento la palabra», y este dato creemos que es de bastante relieve para los estudios léxicos y filológicos en general.

Ya en el Ochocientos, Bartolomé José Gallardo emplea la palabra en el sentido de «conocimiento acerca de las bellas letras»: habla así del «cultivo de la Lengua y Literatura Española» por parte de don Nicolás Böhl de Faber.

\section{«LITERATURA» EN LA LEXICOGRAFÍA NO ACADÉMICA}

Ya queda visto en nuestro trabjo anterior sobre esta materia cómo los Diccionarios académicos que salvo algún leve retoque señalan las etapas de redacción del artículo literatura son los de 1734, 1803, 1837,1884 y 1925 : la idea de que la «literatura» es el arte bello que emplea como instrumento la palabra no aparece hasta el léxico de 1884.

En cuanto a la lexicografía no académica, Aniceto de Pagés registraba tres acepciones de la palabra, a saber: «género de producciones del entendimiento humano, que tiene por fin próximo ó remoto expresar lo bello por medio de la palabra»; «suma de conocimientos adquiridos con el estudio de las producciones de dicha naturaleza; y en sentido más lato, instrucción general en éste y cualesquiera otros de los distintos ramos del humano saber»; «conjunto de todas las producciones literarias de un pueblo ó de una época».

En la primera acepción el autor añade que se consideran comprendidas en tal género de producciones literarias o literatura «la gramática, la retórica, la poesía de todas clases, la novela, la elocuencia y la historia»; en la segunda vemos que se destaca con claridad que literatura es no sólo el conjunto de saberes adquiridos mediante las distintas ramas del conocimiento, sino asimismo el de los adquiridos mediante las bellas letras.

Olimpia Andrés, Gabino Ramos y Manuel Seco consignan a su vez en el Diccionario del español actual del que son autores cinco acepciones presentes en la lengua peninsular de la segunda mitad del siglo $\mathrm{XX}$, y que son: «arte que consiste en la utilización estética del 
lenguaje»; «conjunto de conocimientos relativos a la literatura y a los autores literarios»; «conjunto de (los) escritos [sobre un tema o una materia...]», y en música «conjunto de la producción»; «palabras dichas o escritas con arte o artificio, destinadas a impresionar favorablemente o a disimular una realidad poco grata»; "prospecto o texto explicativo incluido en el envase de un producto farmacéutico». Desde luego todas estas significaciones aparecen autorizadas o documentadas en el presente léxico ${ }^{3}$.

\section{Referencias bibliográficas}

ABAD, F. (2000). Cuestiones de lexicología y lexicografía. Madrid: UNED ( $2 .^{a}$ edición muy aumentada).

3 Las fuentes examinadas en los párrafos anteriores se hallan en nuestra biblioteca particular o las hemos consultado en la Biblioteca Nacional de Madrid (Luzán), y en la Biblioteca Pública del Estado de Málaga. 